\title{
Green Footprint Calibration to Addressing Urban Health While Enhancing Outdoor Thermal Comfort
}

\author{
Sammar Allam ${ }^{1,2}$ \\ ${ }^{1}$ October University for Modern Sciences and Arts, 6th October, Egypt \\ ${ }^{2}$ SHM Studio 16, Cairo, Egypt
}

Received November 1, 2020; Revised March 7, 2021; Accepted March 24, 2021

\begin{abstract}
Cite This Paper in the following Citation Styles
(a): [1] Sammar Allam, "Green Footprint Calibration to Addressing Urban Health While Enhancing Outdoor Thermal Comfort," Civil Engineering and Architecture, Vol. 9, No. 3, pp. 737-746, 2021. DOI: 10.13189/cea.2021.090315.
\end{abstract}

(b): Sammar Allam (2021). Green Footprint Calibration to Addressing Urban Health While Enhancing Outdoor Thermal Comfort. Civil Engineering and Architecture, 9(3), 737-746. DOI: 10.13189/cea.2021.090315.

Copyright $\bigcirc 2021$ by authors, all rights reserved. Authors agree that this article remains permanently open access under the terms of the Creative Commons Attribution License 4.0 International License

\begin{abstract}
In the pursuit of manifesting Sustainable Development Goals (SDG's) set in 2015 by the United Nations, this study attempts to consolidate Goal 11 Sustainable cities and communities through demonstrating a green footprint calibration and enrich urban green infrastructure based on carbon footprint per capita. Carbon Emissions is an escalating issue due to the increasing over population and rapid urbanization. It endangers urban health and contributes to the spread of chronic diseases such as asthma, headaches and vulnerable immune systems. Conceiving green footprint correspondent to carbon footprint does not only convey a pragmatic manifestation of urban health, it also enhances urban thermal comfort. No doubt that one of the main causes of Urban heat island phenomena is the Glass House Gases (GHG). Carbon Sequestration is the main concern of this research utilizing urban thermal comfort indices like PET, UTCI and OutSET while simulating Trees as one of the green infrastructure elements.
\end{abstract}

Keywords Sustainable Development Goals, Urban Thermal Comfort Indices, Green Infrastructure, Green Footprint, Carbon Footprint

\section{Introduction}

Urban Health is a controversial approach to Architects, Urban Designers and citizens. However, promoting urban spaces to be connective and walkable through convenient atmosphere meets the 'urban health' discourse. Green spaces provide shade, equalize temperature through evapotranspiration, and guarantee pleasant air breeze. Hence, adding value to urban health. Designers have innovative solutions to enhance greens into urban areas by adding green vertical, green roofs, and interconnecting green in creative forms.

Water Features have their own influence into public spaces, a livable reference to pedestrians and citizens while it fulfils urban thermal comfort through evapotranspiration.

Connective Cities aims to enhance transportation and encouraging walkability among citizens as transportation contributes to $28 \%$ energy consumption and $25 \%$ carbon emissions in Egypt. Percentages that cannot be ignored, and obligate analytical study and pragmatic solutions in urban design.

Many Researchers collaborative initiative has been compelled to address sustainability issues and calculating inputs and outputs numerically. Regional Sustainability Index (RSI) is using Factor Analysis (FA) with consideration of regional-scale spatial interdependency by employing Local Indicator of Spatial Association (LISA) statistics (Andrea Emma Pravitasari, 2018) [1]

\subsection{Urban Health; SDG's Agenda 2030}

UN has established 17 main sustainable goals for year 2030. Urban Health meets one of SDG's goals or Sustainable Development goals, 11 Sustainable cities and communities. (GBES, 2021) [2]

Urban Health factors have been emphasized by WHO; World Health organization as follows; (World Health 
Organization) (WHO, 2021) [3]

1. Urban governance

2. Population characteristics

3. The natural and built environment

4. Social and economic development

5. Services and health emergency management

6. Food security.

Natural and built environment is the dilemma every designer works on through the design process to create innovative solutions and answers to meet multi-users and citizens of different cultures, traditions, patterns and preferences. Built environments threaten natural ecosystems. However, compensations are valid through urban farms and cultivating built elements to inhabit holistic existence between the natural and built. Builders replace the living with the dead for human to host their intimate spaces.

City centers are another artificial system that require an eco-character to function 'green' and to support healthy environment.

This research encapsulates green elements influence as a natural environment into a new city center as a built one. This city center has become vital, crowded and vulnerable. It encompasses commercial, administrative, educational, health, religious activities. A condensed amalgamation of divers uses that captures visitors and residents and emphasize the solid manifestation of city center.

Natural environments in this urban fabric can be revitalized through endorsing green infrastructure elements to rejuvenate urban health of a crowd, densified and multi-use urban spaces.
Vegetation and water bodies, known as green and blue infrastructure can be an important strategy for shaping sustainable and resilient cities as illustrated by Ahmed Ayad 2019 [4]

\subsection{Green Infrastructure}

Green infrastructure (GI) is a network of multi-functional green space facilities that can increase connectivity between existing natural areas, encourage ecological coherence while improving the quality of life and well-being. (Dr. Adedotun Ayodele Dipeolu, 2020) [6]

Blue, Green and Grey Infrastructures shape more than $50 \%$ of our urban spaces. As per Urban settlement Egyptian law 119, Grey Infrastructure occupies $30 \%$ of total area and the same ratio to housing blocks. Integrating Grey infrastructure with green and blue surfaces promotes urban health.

Green Infrastructure has a more comprehensive meaning rather than just green landscape. It complements all built surfaces through its verticals, horizontals and inclined areas showing its green coverage ability while intruding ins and outs of building blocks, streets and spaces.

Green infrastructure main functions in urban spaces are:

1. Temperature Regulations

2. Storm water runoff mitigation

3. Air Quality Regulation

4. Noise reduction

5. Recreational areas

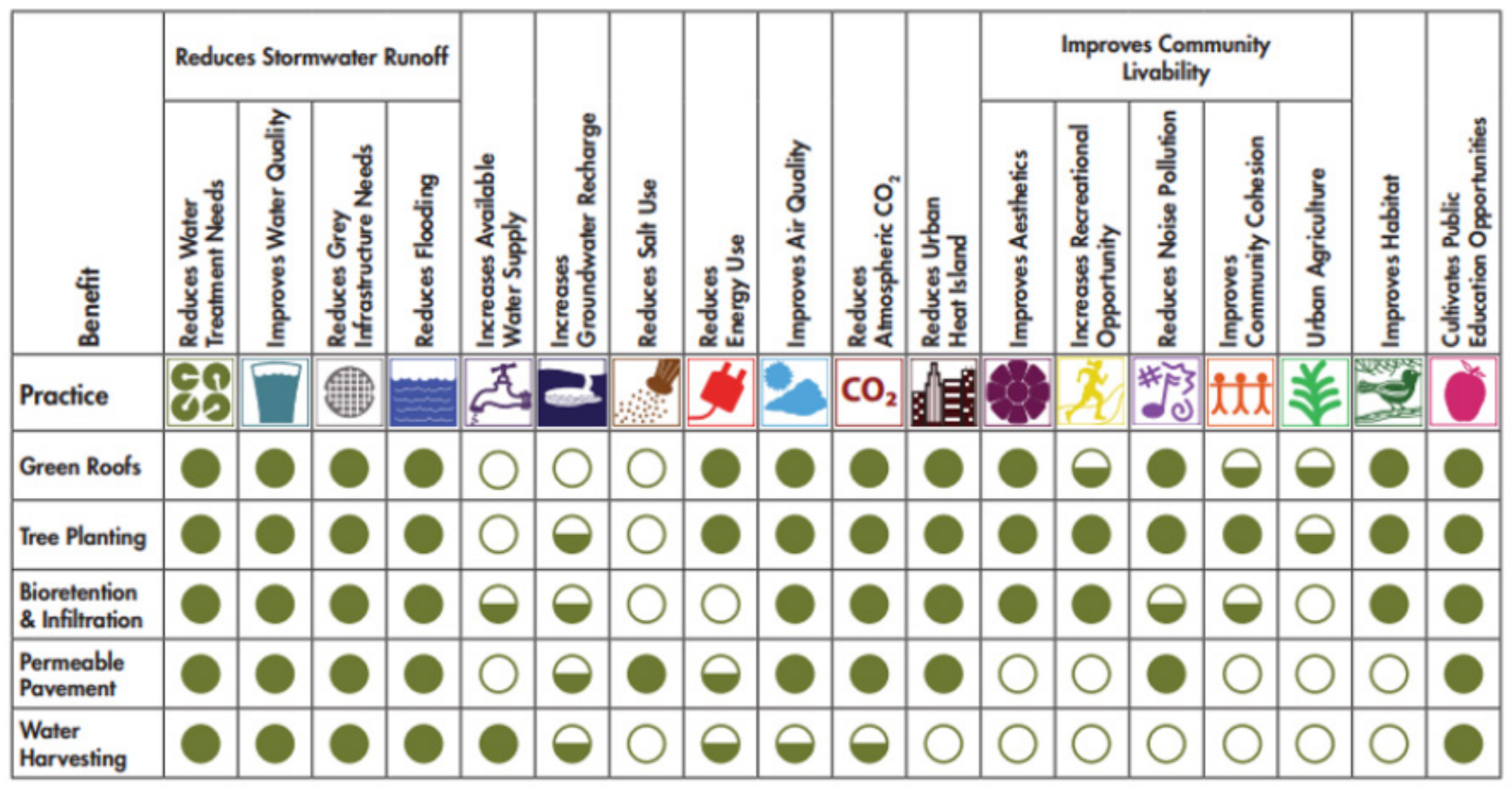

Figure 1. Green Infrastructure benefits by Center of Neighborhood Technology (Winkelman, 2017) [6] 
Trees have three main benefits. They provide shade, act as wind barriers as well as support evapotranspiration. Moreover, Green Infrastructure conveys inter-connected relations through which it upgrades surrounding microclimate and ecosystem.

This research emphasized the usability of trees as a GI element to enhance urban health and stimulate ecosystem continuity. Trees provide shades which mitigate urban hot fever from solar radiations as shown in the following infrared images. Tree Shade and evapotranspiration affect energy fluxed and mitigate microclimate conditions, with beneficial effects on human health and outdoor comfort. (Marco Napoli, 2016) [7]
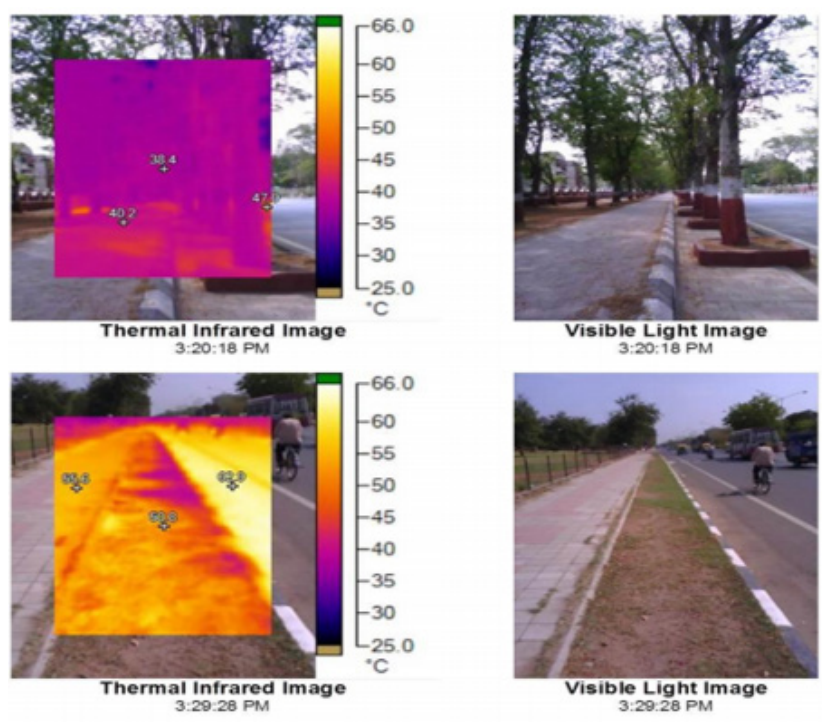

$\underset{3: 20: 18 \text { PM }}{\underset{3}{\text { Visible Light Image }}}$

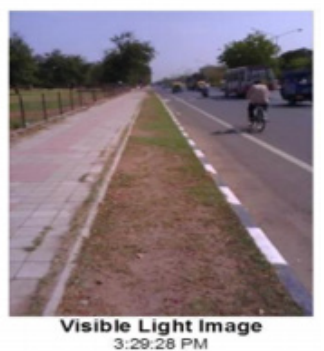

Figure 2. Infrared images show Solar Radiations mitigation due to Tree Shade promoting Cycle lane and Pavements Walkability. (Winkelman, 2017) [6]

\subsection{Urban Thermal Comfort}

Heat stress found in hot arid zones can be enhanced by increasing humidity level, providing shade, and rising surfaces albedos using light paints in addition to water streams and planters. Furthermore, integrating water management from rain runoff and treated wastewater shall bring balance to ecosystem while enhancing comfort in urban spaces.

Green infrastructure has a more comprehensive consolidation. EPA: environmental protection Agency has set elements articulating green infrastructure design. Benefits of Green and blue Infrastructure are to support $\mathrm{CO}_{2}$ absorption that mitigates urban heat island in cities through GHG, glass house gases, dissemination. Nevertheless, it enhances walkable cities through providing shades and minimizing urban heat stress.

Urban thermal comfort indices are divided into two groups (Farajzadeh H, 2015)[8]

1. Simple indices

Simple Indices are like TEK (Equivalent Temperature),
ET (Effective Temperature), WCT (Wind Chill temperature), WBGT (Wet-Bulb-Globe-Temperature), and Humidex.

TEK evaluates the common effect of air temperature and vapor pressure on human organism and is defined as a temperature required for air (in constant air pressure) if all its containing vapor was condensed.

Wind chill index WCI (W m-2) was calculated, expressing the cooling power of the wind in complete shade and without any evaporation, as is suggested in ISO TR 11079 (1993). This led to the development of wind chill temperature (WCT) (ASHRAE, 1997) (H. Farajzadeh, 2015) [8]

Wet-bulb-globe-temperature (WBGT) was developed by the US Navy as part of a study on heat-related injuries during military training (Yaglou CP, 1957) [9]

2. The indices derived from energy budget models to measure energy balance models. While indices derived from energy budget models are PET, SET, PST, and STI.

\section{PET}

The physiological equivalent temperature (PET) is based on the Munich Energy-balance Model for Individuals (MEMI), which models the thermal conditions of the human body in a physiologically relevant way. PET is defined as the air temperature at which, in a typical indoor setting (without wind and solar radiation), the heat budget of the human body is balanced with the same core and skin temperature as under the complex outdoor conditions to be assessed. (Höppe, 1999) [10]

On hot summer days, for example, with direct solar irradiation the PET value may be more than $20 \mathrm{~K}$ higher than the air temperature, on a windy day in winter up to $15 \mathrm{~K}$ lower.

The Munich energy balance model for individuals" (MEMI) (Höppe P., 1993)[10] is such a thermo-physiological heat balance model. It is the basis for the calculation of the physiologically equivalent temperature (PET). In detail the MEMI model is based on the energy balance equation (9.1) for the human body: (Matzarakis A., 2008) [12]

$$
\mathrm{M}+\mathrm{W}+\mathrm{R}+\mathrm{C}+\mathrm{ED}+\mathrm{ERe}+\mathrm{Esw}+\mathrm{S}=0 \text {-----Equation-3 }
$$

Where, $M$ the metabolic rate (internal energy production),

W the physical work output,

$\mathrm{R}$ the net radiation of the body,

$\mathrm{C}$ the convective heat flow,

ED the latent heat flow to evaporate water diffusing through the skin (imperceptible perspiration),

ERe the sum of heat flows for heating and humidifying the inspired air,

$\mathrm{ESw}$ the heat flow due to evaporation of sweat, and

$\mathrm{S}$ the storage heat flow for heating or cooling the body 
mass.

The individual terms in this equation have positive signs if they result in an energy gain for the body and negative signs in the case of an energy loss ( $\mathrm{M}$ is always positive; W, ED and Esw are always negative). The unit of all heat flows is in Watt (Höppe 1999) [10].

The individual heat flows in Equation-3, are controlled by the following meteorological parameters (Verein Deutscher Ingenieure 1998; Höppe 1999): [10]

- Air temperature: C, Eer

- Air humidity: ED, ERe, ESw

- Wind velocity: C, ESw

- Mean radiant temperature: $\mathrm{R}$

\section{UTCI}

The Universal thermal climate index (UTCI) is a temperature equivalent for a given combination of wind, radiation, humidity and air temperature is defined as they are temperature in the reference condition of humidity, radiation and wind speed. (Jendritzky, 2012)[13]

$$
\mathrm{UTCI}=\mathrm{f}(\mathrm{Ta}, \mathrm{va}, \mathrm{Pa}, \text { Tmrt-Ta }) \ldots . .(\text { Function } 1)
$$

- Ta: air temperature $\left(0\right.$ to $\left.+50^{\circ} \mathrm{C}\right)$

- Tmrt: mean radiant temperature $\left(30^{\circ} \mathrm{C}\right.$ above air temperature)

- va: wind speed $(0.5$ to $17 \mathrm{~m} / \mathrm{s})$

- Pa: humidity in kpa (below $100 \%$ relative humidity)

It calculates the Universal Thermal Climate Index (UTCI) for a set of input climate conditions. It is one of the urban thermal comfort indices to be explained more later.

UTCI is this temperature of what the weather "feels like" and it takes into account the Mean radiant temperature (sometimes including solar radiation), relative humidity, and wind speed. (grasshopper3d.org)[14]

This calculator results a numerical value for each day based on the mean radiant temperature calculated by direct and diffused radiations projected on a cumulative sky matrix. It provides accurate values of UTCI. One of its output as well the percentage of comfort during a series of days concerning the study which can be selected to study outdoor comfort in summer daytime.

Two main parameters that affect these urban thermal comfort indices readings and change the first is the mean radiant temperature, and the second is the albedo which will be illustrated as follows

\section{Mean Radiant Temperature}

It is the most important meteorological parameter that is affecting the human thermal comfort. The mean radiant temperature (Tmrt) is determined by an integral radiation measurement. Tmrt can be determined if the total of all absorbed radiant flux densities (Srad) is known. In order to calculate Srad, short-wave and long-wave radiation fluxes are derived respectively.

\section{Tmrt $=[$ Srad $\varepsilon * \sigma] 0.25-273.1\left({ }^{\circ} \mathrm{C}\right)($ Function 3$)$}

Tmrt: Mean radiant temperature

$\varepsilon$ : Emissivity of human body (0.97)

$\sigma:$ Stefan-Boltzmann constant $(5.67 * 10-8 \mathrm{Wm}-2 \mathrm{k}-4)$

Since model cannot produce UTCI thermal results, this operation is implemented in the R software as a numerical approximation to the calculation of UTCI.

Table 1. Ranges of the physiological equivalent temperature (PET) for different grades of thermal perception by human beings and physiological stress on human beings; internal heat production: $80 \mathrm{~W}$, heat transfer resistance of the clothing: 0.9 cloth (According to Matzarakis and Mayer 1996) [15]

\begin{tabular}{|c|c|c|}
\hline PET & Thermal perception & Grade of physiological stress \\
\hline & Very cold & Extreme cold stress \\
$4^{\circ} \mathrm{C}$ & Cold & Strong cold stress \\
$8^{\circ} \mathrm{C}$ & Cool & Moderate cold stress \\
$13^{\circ} \mathrm{C}$ & Slightly cool & Slight cold stress \\
$18^{\circ} \mathrm{C}$ & Comfortable & No thermal stress \\
$23^{\circ} \mathrm{C}$ & Slightly warm & Slight heat stress \\
$29^{\circ} \mathrm{C}$ & Warm & Moderate heat stress \\
$35^{\circ} \mathrm{C}$ & Hot & Strong heat stress \\
$41^{\circ} \mathrm{C}$ & Very hot & Extreme heat stress \\
\hline
\end{tabular}

Table 2. Adaptive Comparative Analysis between different urban thermal comfort indices group 2; derived from energy budget models, (grasshopper3d.com) [14]

\begin{tabular}{|c|c|c|c|}
\hline Index & & Input & Scale Factor \\
\hline PET & \multirow{4}{*}{\multicolumn{2}{|c|}{$\begin{array}{ll}\text { 1. } & \text { Dry Bulb Temp. } \\
\text { 2. } & \text { MRT } \\
\text { 3. } & \text { Wind speed } \\
\text { 4. } & \text { Relative humidity } \\
& \text { Can take } \\
\text { 1. } & \text { Metabolic Rate } \\
\text { 2. } & \text { Clothing level }\end{array}$}} & $\begin{array}{l}<4 \mathrm{C}-\text { Cold Stress } \\
>41 \mathrm{C}-\text { Heat Stress } \\
18-23 \text { C- Comfort }\end{array}$ \\
\hline PMV & & & Scale Factor \\
\hline UTCI & & & $\begin{array}{l}<4 \mathrm{C}-\text { Cold Stress } \\
>41 \mathrm{C}-\text { Heat Stress } \\
18-23 \mathrm{C}-\text { Comfort }\end{array}$ \\
\hline SET & & & Scale Factor \\
\hline
\end{tabular}

\subsection{Carbon Footprint}

Tree plantations absorb carbon dioxide from the atmosphere, and the humid tropics with year-round warmth and moisture are by far the best place for fast-growing tree plantations. According to Myers and Goreau, tropical tree plantations of pine and eucalyptus can sequester an average of 10 tons of carbon per hectare per year. (Myers, 1991) [16] Ten tons of carbon per acre per year for tropical areas while Egypt is mainly subtropical except of the southern region of upper Egypt can be considered tropical (Nations Encyclopedia, 2020) [17] Mangrove forests are highly productive, with carbon production rates equivalent to tropical humid forests. (Alongi 2014) [18] Mangrove is one of the indigenous trees together with Carob tree that are evergreen. The mangroves in Egypt occupy about 525 hectares distributed in 28 different locations along Egyptian Red Sea coasts. One large discontinuous stand along the Gulf of Aqaba in 
Nabq Protected Area and one small stand at the most southern part of Gulf of Suez at Ras Mohammed National Park (Zahran 2009) [19]. Hence, shaded streets together with low maintenance are guaranteed with cultivating native species.

Egypt GHG emission in 2000 has been calculated to be 193.3 million tons as illustrated in table 3 . Hence, carbon footprint in GHG emission has increased to be $288 \mathrm{Mt}$ $\mathrm{CO}_{2} \mathrm{e}$ in 2012 (USAID 2012) [20]. At the same time, carbon in Egypt is $3.57 \mathrm{t} \mathrm{CO}_{2}$ e per capita. The world carbon footprint is $6.76 \mathrm{t} \mathrm{CO}_{2}$ e per capita which concludes that Egypt has almost half the world value.

Table 3. Egypt's GHG emissions by gas Type for the year 2000 (USAID 2012) [20]

\begin{tabular}{|c|c|c|}
\hline $\mathrm{Gas}$ & Emissions $\left(\mathrm{MtCO}_{2} \mathrm{e}\right)$ & Emissions (\%) \\
\hline $\mathrm{CO}_{2}$ & 128.2 & 66.3 \\
\hline $\mathrm{CH}_{4}$ & 39.4 & 20.4 \\
\hline $\mathrm{N}_{2} \mathrm{O}$ & 24.4 & 12.6 \\
\hline $\mathrm{PFC}$ & 1.1 & 0.6 \\
\hline $\mathrm{SF}_{6}$ & 0.1 & 0.1 \\
\hline $\begin{array}{c}\mathrm{HFC} \text { 's } \\
\text { blend }\end{array}$ & 0.1 & 0.1 \\
\hline Total & 193.3 & 100 \\
\hline
\end{tabular}

On Contrary, if Egypt carbon emission is 128.2 is divided by its population 98, 000. Then, carbon footprint is $0.0013 \mathrm{Mt} \mathrm{CO}_{2}$ e which will be utilized to calculate green footprint later in the research.
This research investigates SDG's goal, Urban Health through Green and Blue infrastructure integration into urban realm with a focus on tree allocations and multi-functionalities on the urban thermal comfort through measuring urban indices.

Research Methodology can be organized in the following steps:

1. Explore solar radiation analysis in street canyon with and without trees using Cairo weather file

2. Select a study area (El-Hosary and $6^{\text {th }}$ October University) as an urban active center that will encourage walkability among university students.

3. Investigate tree allocation in Street canopies in the study area

4. Comparing results using urban thermal comfort indices to study tree effect to microclimate and Evapotranspiration effect

\subsection{Site Selection}

El-Hosary square or El-Hosary area is an urban center for $6^{\text {th }}$ October city. It encompasses commercial centers, $6^{\text {th }}$ October University and the most significant place of all is El-Hosary Mosques upon which this area or zone has been called after.

Collapsing existing urban infrastructural facilities or complete lack of them in some urban centers, indiscriminate change of use, lack of use, abuse of use, unused and disuse of urban lands (Dr. Joseph Adeniran Adedeji, 2018) [21]. Hence, El-Hosary area urban redevelopment takes place through demonstrating GI through integrating tree vegetation on street sides to benefit shaded walking spaces and enhance carbon absorption.

\section{Methodology}

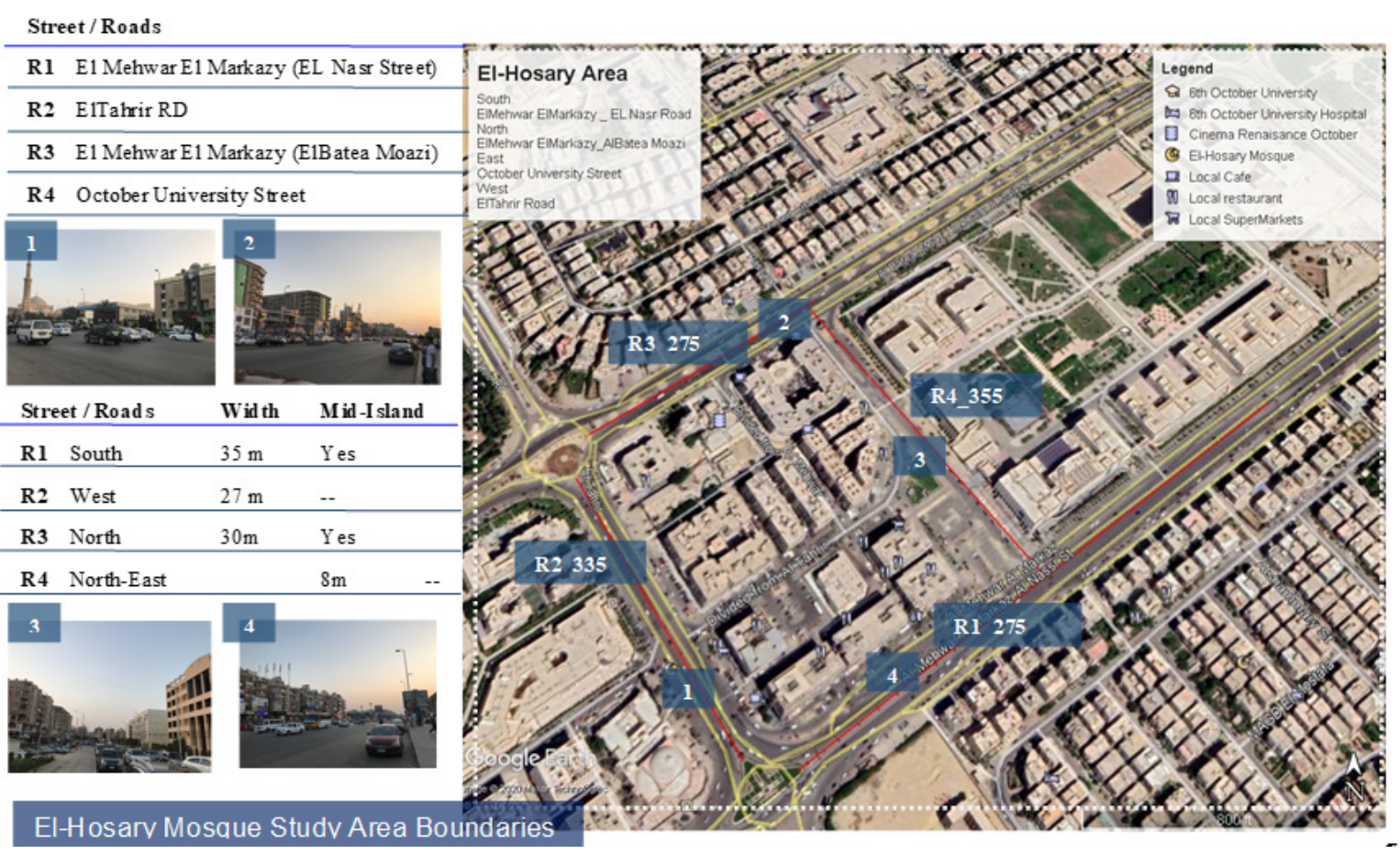

Figure 3. Area of study boundary streets parameters. 


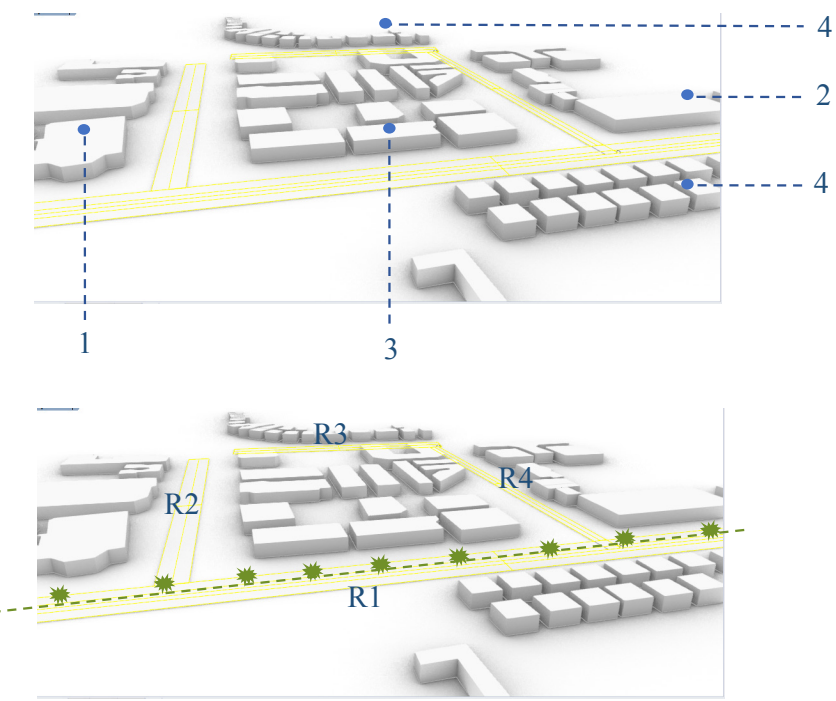

$\frac{\text { Land Use }}{1 .}$
$\begin{aligned} & 2 . \text { El-Hosary Mosque } \\ & \text { 6h } \text { October University Campus } \\ & \text { Commercial } \\ & \text { (Restaurants/Café/Shops) } \\ & \text { Residential (Housing) }\end{aligned}$
Green Infrastructure Study
$\mathrm{R} 1=243 \mathrm{~m} \quad \mathrm{R} 3=275 \mathrm{~m}$
$\mathrm{R} 2=335 \mathrm{~m} \quad \mathrm{R} 4=355 \mathrm{~m}$
1. Investigate tree allocation effect on
1.1 Solar Radiation Analysis
1.2 Urban Thermal Comfort
Indices

Figure 4. Selected Site (El-Hosary) Urban Analysis; inscribed area limits and boundaries

The area of study acts as a vibrant city center to $6^{\text {th }}$ October city. It captivates commercial, religious, administrative, health, educational and recreational uses and magnets to city residents and visitors. It is a highly densified yet polluted area due to its crowded streets and neglected urban features.

\subsection{Tree Shade Simulation}
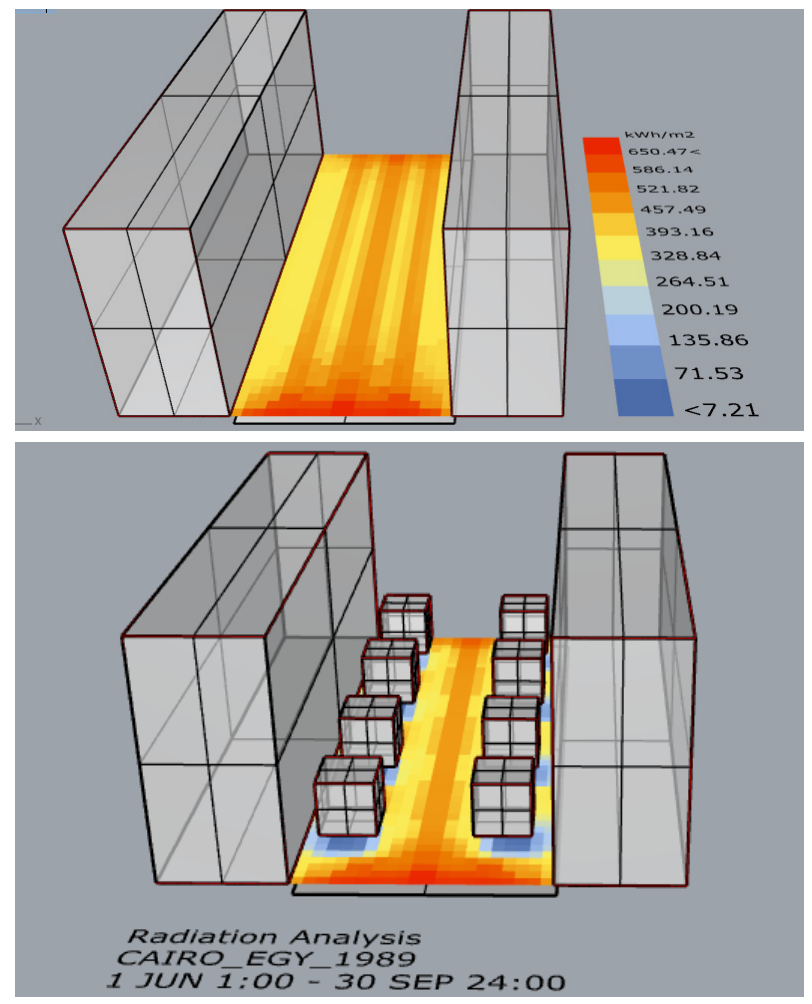

Figure 5. (a) Solar Radiation analysis in a street canyon with no trees (b) Solar radiation analysis in a street canyon with trees

Trees are one of the green infrastructure elements that worth its maintenance and consumed water. Vertical vegetations not only provide shades but they act also as a natural barrier against unfavorable wind. Moreover, it improves air quality through its evapotranspiration effect.

An experiment has taken place in an urban canyon with and without tress. Solar radiation with no trees while simulating Cairo weather file is $410.2 \mathrm{kWh} / \mathrm{m}^{2}$. A street canyon with trees on each side has a solar radiation up to $312.9 \mathrm{kWh} / \mathrm{m}^{2}$. Solar radiation has been reduced by $21.53 \%$ which can benefit enhancing outdoor thermal comfort.

\subsection{Carbon Footprint -to- Green Footprint}

Trees for the Future estimate that our agroforestry trees, planted in tropical climates, will sequester atmospheric carbon dioxide at an average of 50 pounds of carbon dioxide per tree per year. (Future 2020) [22] which is equivalent to 0.025 ton.

Calculating Egypt carbon foot print per capita while linking it to the number of residents in the area of study leads us to the number of trees required to absorb or mitigate carbon emissions per capita which is called green footprint.

Each resident living in an area is required to be substitute with tree vegetation to support climate change and reduce carbon foot print through carbon sequestration.

\section{Results}

Radiation analysis measures in four boundary streets of the area of study have shown the same results tried in the experimental zone made earlier. Trees coverage area is 4.5 X4.5 m every 8-9 meters interval. R1 street is the main street with the highest density in vehicle has a mid-Island. Hence, more trees have been added on the mid-Island of a total 60 trees in the whole area. Measurements has found 
almost $21 \%$ of solar radiation is reduced in $\mathrm{R} 1$ and $\mathrm{R} 2$ located on the south and west boundaries of the area of study. The northern and northern east boundaries have no severe solar radiation due to their cardinal orientation. However, both streets R3 and R4 are crowded with pedestrians, commercial and multiple activities which require trees induction to balance carbon sequestration through a green footprint manifestation.

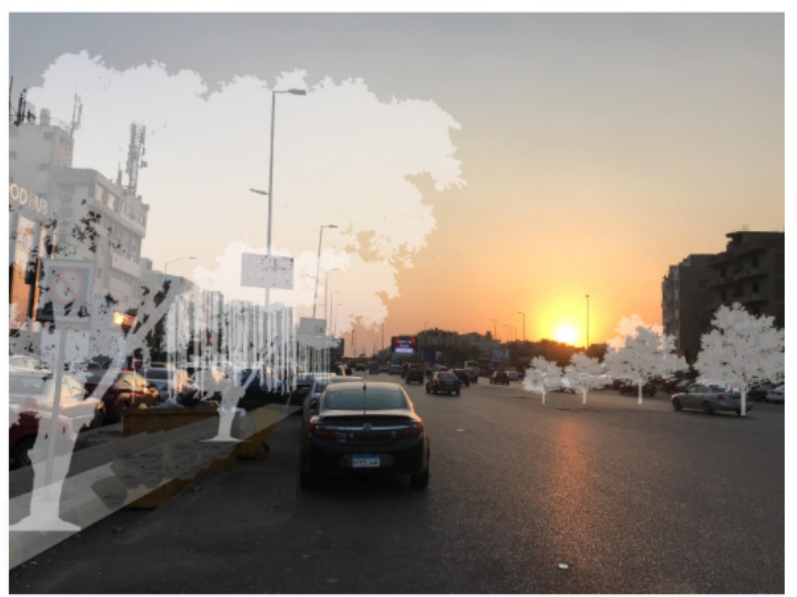

Figure 6. Case study area modified shot after adding trees on both sides
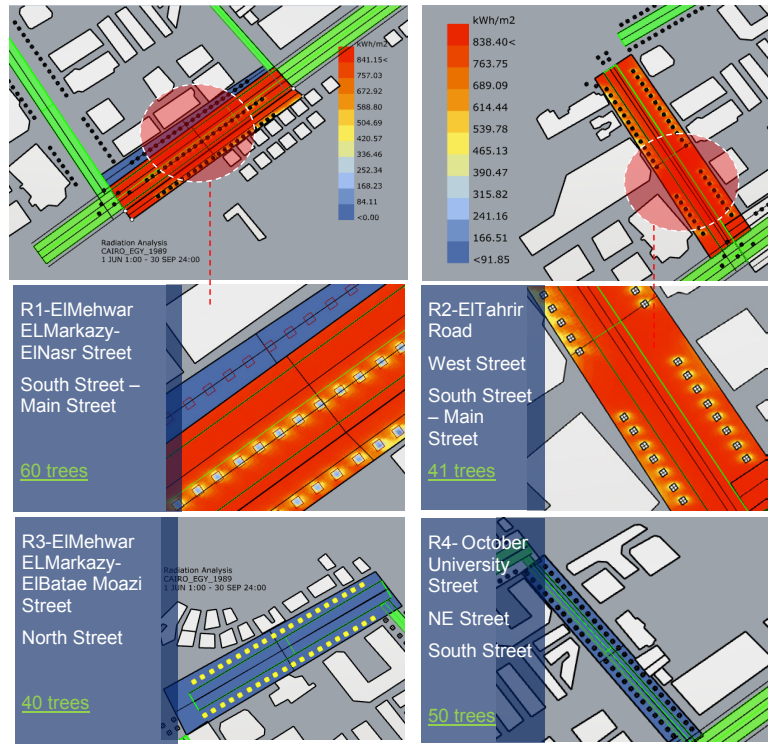

Figure 7. Solar Radiation simulation in the boundary streets for the area of study
Simultaneously, Tree vegetation on streets' sides and middle island enhances urban thermal comfort through adding shade as delineated in figure 6 and 7 and more significant through carbon sequestration which reduce GHG effect on urban spaces while mitigating urban heat island (UHI) phenomenon.

Urban Regeneration through enhancing green infrastructure and upgrading the urban fabric with natural ecosystem element is manifesting SDG Goal 11. Nevertheless, providing shaded areas encourages walkability as the case study area incorporates low-rise buildings which can easily be integrated with trees while nourish city-center skyline with dominant natural elements.

Hence, it addresses mobility issues and emphasizes livability in the urban life at dense city-centers.

\subsection{Green Footprint Calibration}

Calibrating green footprint as illustrated earlier is essential to recognize the required numbers of trees to cover carbon footprint per capita and mitigates GHG emissions with carbon sequestration.

$6^{\text {th }}$ October density is expected to be 202,945 in 2019 distributed on an area of $228 \mathrm{~km}^{2}$ (studies 2019) [23]. Area of study is bounded within about $97 \mathrm{~km}^{2}$. Hence, its density is 85,000 capita. A green footprint calculation is estimated to allocate 4448 trees.

Design simulation has located 191 trees in four streets. All trees are distributed on streets side except for R1 it included the mid-island as it is considered as a main street for this city center.

\subsection{PET}

Measuring PET for Cairo Weather which indicates the Heat Stress with PET $>40.3 \mathrm{C}$ slightly in April, May and till September as shown in figure 8.

Hence, more detailed analysis study for PET index has been carried out during these specific months from April till September, while modifying the legend to highlight readings from $20 \mathrm{C}$ till $45 \mathrm{C}$ as the heat stress is considered for PET to be above $41 \mathrm{C}$ as illustrated in figure 8 and 9.

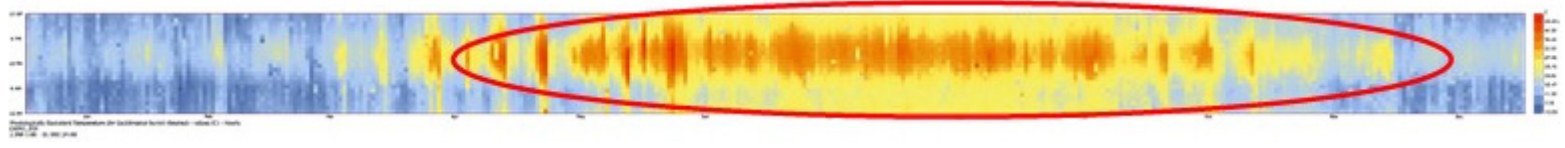

Figure 8. PET for Cairo weather file throughout the whole year. 


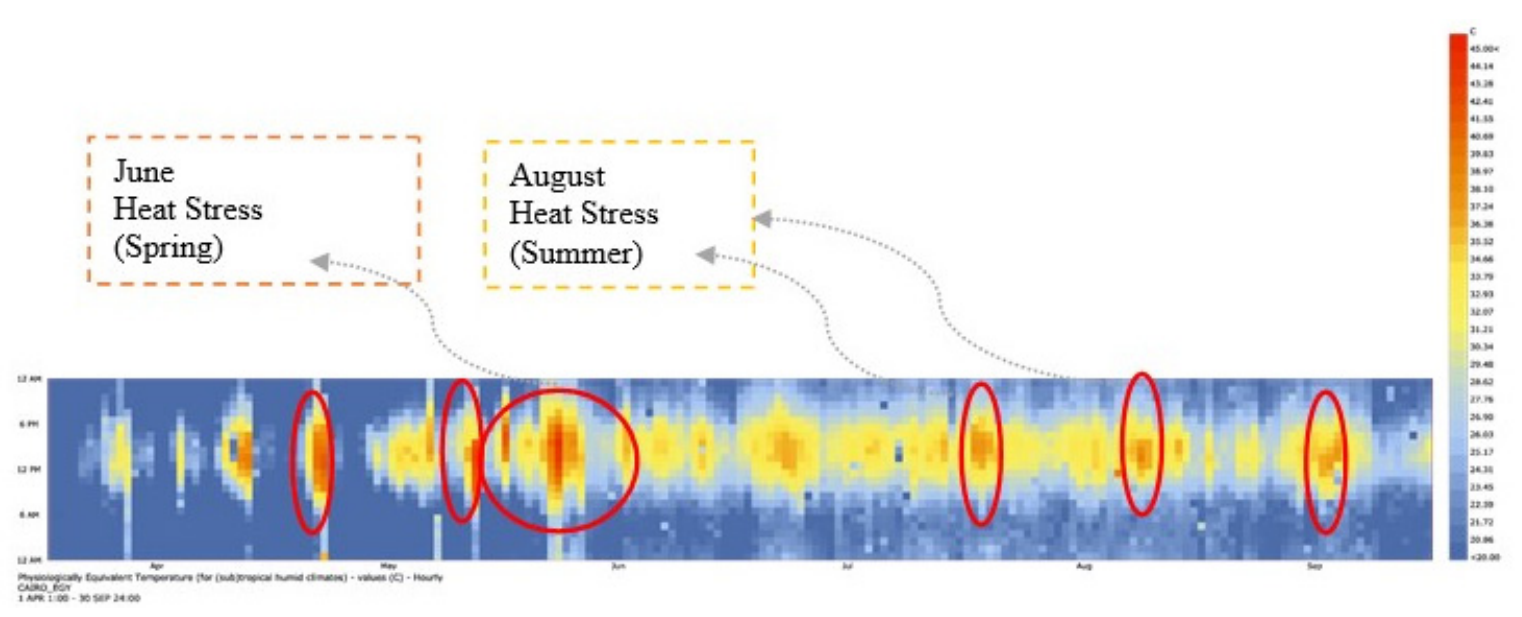

Figure 9. PET for Cairo weather file from April-till-September

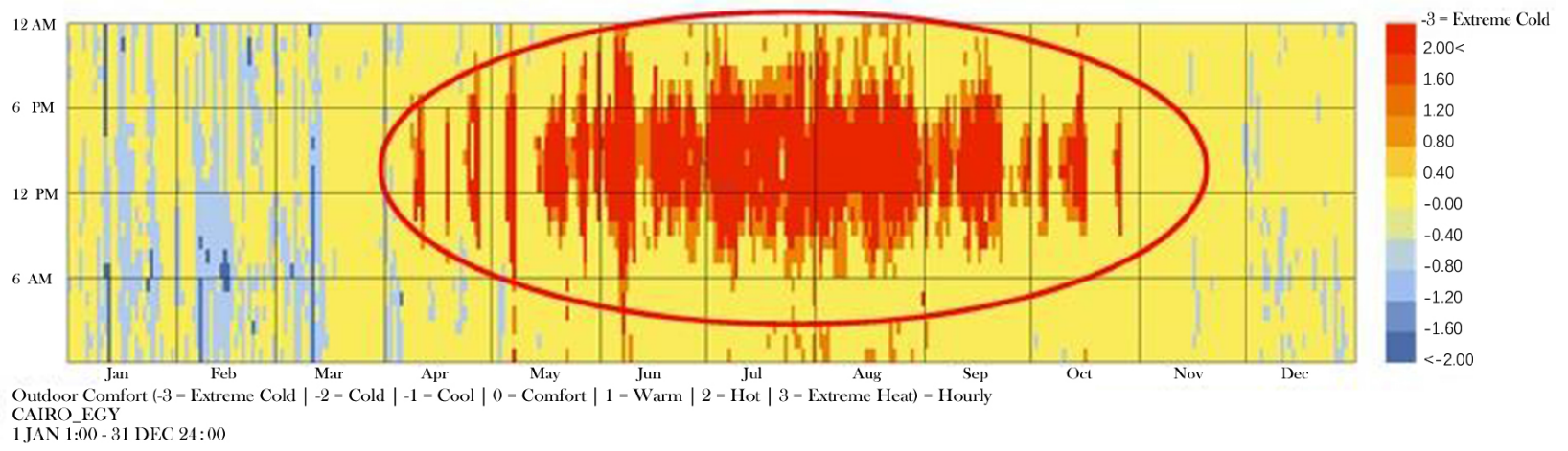

Figure 10. Outdoor Comfort Calculator results

After simulation trees canopy, ad decrease in solar radiation by almost $21 \%$ shall affect wind speed, relative humidity concentration in air, and dry bulb temperature to affect PET results. Assuming 21\% of values decrease like solar radiation. Urban spaces thermal comfort shall be convenient for outdoor activities while stimulating walkability in the city center. This Area (Elhosary Mosque Square) has witnessed high thermal street in late summer 2019 in which university called an emergency early dismissal by $2: 00 \mathrm{pm}$.

The Middle East is a hot, arid region that is also very vulnerable to extreme heat. Some towns on the coast of the Persian Gulf have already experienced temperatures of $1500 \mathrm{~F}(650 \mathrm{C})$ ! They are on their way to becoming uninhabitable. (Faia, 2019)[24]

\subsection{UTCI}

An analysis of outdoor comfort in June till September shows that $43 \%$ of year faces heat stress, while $0 \%$ of time faces cold stress; below 0 degree. These results make sense with the known weather in summertime.

UTCI is the most reliable index to evaluate outdoor thermal comfort as it intakes relative humidity, wind speed at 10 meters, mean radiant temperature, and dry bulb temperature. Since vegetation alters air humid concentration in addition to providing shade, these factors are enough to alter thermal flux in the urban context. Microclimate improves due to solar radiation mitigation as illustrated before.

According to the changing thermal flux, the $43 \%$ of heat stress will be mild to be tolerable by residents while encourage city center activities and promote healthy urban forms.

Integrating green Infrastructure mitigates this heat stress. Infrastructure development considers the main pivot for achieving this concept, where, the development in this sector reflects communities' growth and welfare [25] Green Infrastructure is restoring the natural ecosystem equilibrium. Moreover, Blue infrastructure as well can be another pillar to work on whenever it is pragmatic and feasible to implement in the absence of water sacristy.

\section{Conclusions}

Green infrastructure can easily be integrated to our urban spaces to promote urban health. Connective cities are achievable through measuring UTCI of our urban areas while adjusting results by inducing tropical trees like mangrove and carob to provide shade and enhance outdoor thermal comfort. Green footprint calibration can assist consolidating natural environment to sustain built one. 


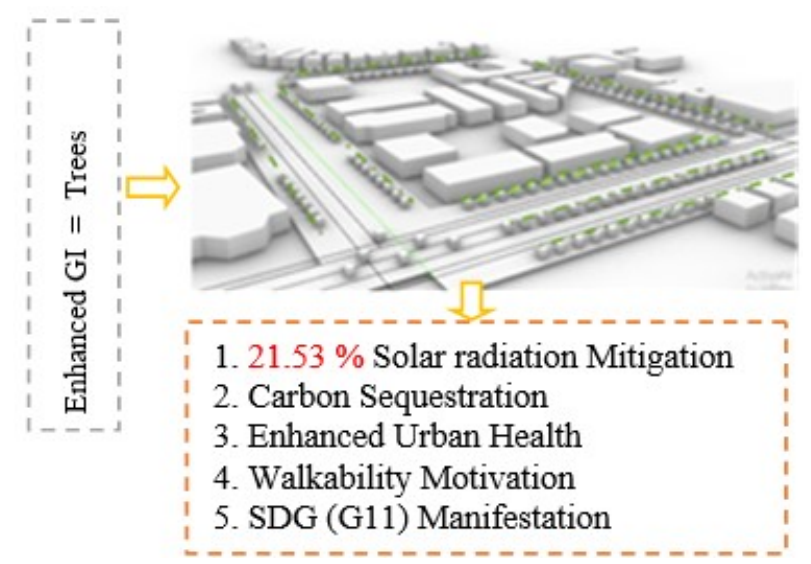

Figure 11. Case study area modified shot after adding trees on both sides

City center as a densified area shall be densified with trees as well to overcome GHG hazards and act as a green node in the urban fabric instead of a troublesome one as delineated in figure 11. Crowded areas with intense activities hold high thermal stress. Tree shades mitigate solar radiation by $21.53 \%$. Indigenous tropical or evergreen trees can present residents' green footprint through pragmatic and holistic perspective.

Indigenous tropical Trees are still not enough to solve urban health issues related to built and natural environment. Tree was a reference to the natural world as the tallest element in natural habitats that can cover hills and follow land contours. On the other side, the scenario of built environment entails high buildings that can inhabit more sophisticated green infrastructure to compensate massive built blocks while supports carbon or GHG sequestration.

\section{Acknowledgments}

I am grateful to my mentor Professor Mohammed Assem Hanafi for his continuous support and guidance. Authors are grateful to all active and sincere personnel drawing the roadmap to sustainable development and setting its goals. Green footprint is under the protection as a patent registered 21 February 2021 by the Egyptian Patent Office resident at 101 Kasr ElEiny, Cairo, Egypt

\section{REFERENCES}

[1] Andrea Emma Pravitasari, E. R. (2018). Developing Regional Sustainability Index as a New Approach for Evaluating Sustainability Performance in Indonesia. Environment and Ecology Research, 157-168. doi:10.13189/eer.2018.060303

[2] GBES. (2021, 02 21). United Nations Sustainable Development Goals (SDG 2030). Retrieved from GBES: https://www.gbes.com/blog/united-nations-sustainable-deve lopment-goals/

[3] WHO. (2021, 02 21). Urban Health. Retrieved from World Health Organization (WHO): https://www.who.int/health-to pics/urban-health

[4] Ahmed Ayad, M. F. (2019). Urban Green and Blue Infrastructure Simulation in a Changing Climate from Microclimate. 16th IBPSA international Conference and Exhibition (pp. 3499-3507). Italy: IBPSA. doi:https://doi.org/10.26868/25222708.2019.210676

[5] Dr.Adedotun Ayodele Dipeolu, D. M. (2020). Mitigating Environmental Sustainability Challenges and Enhancing Health in Urban Communities: The Multi-functionality of Green Infrastructure. Journal of COntemporary Urban Affairs, 33-46.

[6] Winkelman, S. (2017). Blue, Green and Grey Infrastructure: Examples and benefits. Victoria: Livable Cities Forum, Victoria, BC.

[7] Marco Napoli, L. M. (2016). Modeling Tree Shade Effect on Urban Ground Surface Temperature. Journal of Environmental Quality, 146-156.

[8] H. Farajzadeh, M. Saligheh, B. Alijani, A. Matzarakis,Comparison of selected thermal indices in the northwest of Iran, Nat. Environ. Chang, 1 (2015), pp. 1-20

[9] Yaglou CP, Minard D (1957) Control of heat casualties at military training centers. Arch Ind Health 16:302-316

[10] P. Höppe, The physiological equivalent temperature-a universal index for the biometeorological assessment of the thermal environment,Int. J. Biometeorol, 43 (1999), pp. $71-75$

[11] Höppe, P.R. Heat balance modelling. Experientia 49, 741746 (1993). https://doi.org/10.1007/BF01923542

[12] Matzarakis A., Amelung B. , Physiological Equivalent Temperature as Indicator for Impacts of Climate Change on Thermal Comfort of Humans, Seasonal Forecasts, Climatic change and Human health, Springer, pp 161-172,2008

[13] Jendritzky, G., de Dear, R. \& Havenith, G. UTCI-Why another thermal index?. Int J Biometeorol 56, 421-428 (2012). https://doi.org/10.1007/s00484-011-0513-7

[14] www.grasshopper3d.org (Accessed Nov. 29,2020)

[15] Myers, N. T. (1991). TROPICAL FORESTS AND THE GREENHOUSE EFFECT: A MANAGEMENT RESPONSE. Climat Change, 215-226.

[16] Nations Encyclopedia. (2020). Retrieved from Egypt -Climate:

https://www.nationsencyclopedia.com/Africa/Egypt-

[17] Alongi, D. M. (2014). Carbon sequestration in mangrove forests. Carbon Management Review, Future Science, 313-322. doi: $10.4155 / \mathrm{cmt} .12 .20$

[18] Zahran, M. A. (2009). The vegetation of Egypt. (Vol. 2nd edition). Springer. doi:10.1007/978-94-015-8066-3

[19] USAID. (2012). Greenhouse Gas Emissions in Egypt. EGYPT: USAID, United States Agency International Development. 
[20] Dr.JOSEPH ADENIRAN ADEDEJI, D. A. (2018). Urban Renewal Strategies and Economic Growth inOndo State, Nigeria: A Case Study. Journal of Contemporary Urban Affairs, 76-83.

[21] Future, T. f. (2020). Tree carbon Sequestration. Retrieved 10 30, 2020, from http://www.tree.org

[22] itsliquid. (2013, 11 29). PNU BY PERKINS+WILL. Retrieved 2019, from https://www.itsliquid.com: https://www.itsliquid.com/princess-nora-university.html

[23] Studies, G. (2019, 07 01). City Population. Retrieved 10 30,
2020, fromhttps://www.citypopulation.de/en/egypt/greaterc airo

[24] Faia, D. K. (2019). Urban Heat in the Anthropocene: Coming Soon to Your City. Environment and Ecology Research, 43-58. doi:10.13189/eer.2019.070105

[25] Ahmed M. Selim, Doha M. Saeed (2021). Infrastructure Projects for Green Cities between Implementation Challenges and Efficiency Indicators. Civil Engineering and Architecture, 9(2), 347 - 356. DOI: 10.13189/cea.2021.090208. 